\title{
NEW DESIGN OF THE EVOLVENT WORM MILL WITH CARBIDE TURNING RACK
}

\author{
O. I. Boriskin ${ }^{1}$, I. V. Astapova ${ }^{1}$ \\ ${ }^{1}$ Tula State University (Tula, Russia) \\ E-mail:polyteh2010@mail.ru; goriv1356@gmail.com
}

\section{Introduction}

Gears are one of the most critical parts of most components and mechanisms, so the requirements for their accuracy are increasing at the present stage of development of mechanical engineering. A significant impact on the quality of gears is played by accuracy, durability and reliability of cutting tool [1-3].

In most cases of machining gears, the most common is the process of milling with worm cutters with carbide-tipped hob cutters [4-6]. Worm milling cutters are the most promising tool, as they provide the highest productivity of machining gears in mass and large-scale production.

A lot of research are devoted to questions of improving the process of processing gears with worm mills [7-11].

Currently, the most widely used are mills with the cutting elements in the form of racks. Prefabricated worm cutters with solid gear racks have several advantages over prefabricated milling cutters with other cutting elements. The main advantage is more rigid, easy to manufacture and technologically advanced design. However, the studies of the geometric accuracy of the profile of such cutters showed that the significant errors in the profile of the producing surfaces of the cutter (main worm) arise as a result of the rotation of the rack with respect to its longitudinal axis. Therefore, the existing designs of such cutters are used only for roughing or semi-finishing.

Since carbide tools require hardening of the cutting edges, carbide worm milling cutters must have negative rake angles.
Theoretically accurate cutting edges of the cutter should coincide with the intersection lines of theoretically accurate surfaces of the main worm with the adopted flat front surface. The intersection lines of the lateral surfaces of the turns of the main worm with the adopted front surface, which does not pass through the axis of the worm, will be nonsymmetric and curved at the same time. For technological reasons curved cutting edges are approximated by straight line segments. Moreover, the inclination angles of the cutting edges of the cutter in the front plane (profile angles) will be different [12] for both positive and negative rake angle.

Thus, when the criteria for blunting the cutter are achieved and the rack is rotated $180^{\circ}$ with respect to the longitudinal axis, its new edges will not coincide with the original ones. As a result of rotation there are significant distortions in the profile of the main worm, which are transferred to the tooth profile of the workpiece.

In order to avoid these deviations, the design of a prefabricated involute worm cutter with solid rails, which allows to reduce the consumption of hard alloy, is proposed.

\section{The design of evolvent worm cutter with carbide racks}

The design of the prefabricated worm cutter is shown in Fig. 1. In order to reduce the consumption of scarce hard alloys, it is proposed to use racks with the calculated theoretically required tooth profile (Fig. 2). In this case, it is necessary to use two completely identical working buildings. But one of them will be left-handed and the other right-handed. 
In addition to working bodies and a kit of racks, the worm mill consists of plates 3 , screws 2, support plates 5 and support plates 6...9. The mutual displacement of the racks along the helical line is provided with the support plates 5 having protrusions of different lengths in opposite to each groove. Chip grooves have been adopted parallel to the axis, which are the most technologically advanced and easy to operate.

The advantages of this design are as follows:

- the reliable fixation of teeth in the axial direction with plates and screws;

- the displacement of the cutting edges of the rack along the helix is provided using the support plates 5 with a variable length of the protrusions;

- the ability to restore the diameter of the cutter with pads during cutting elements
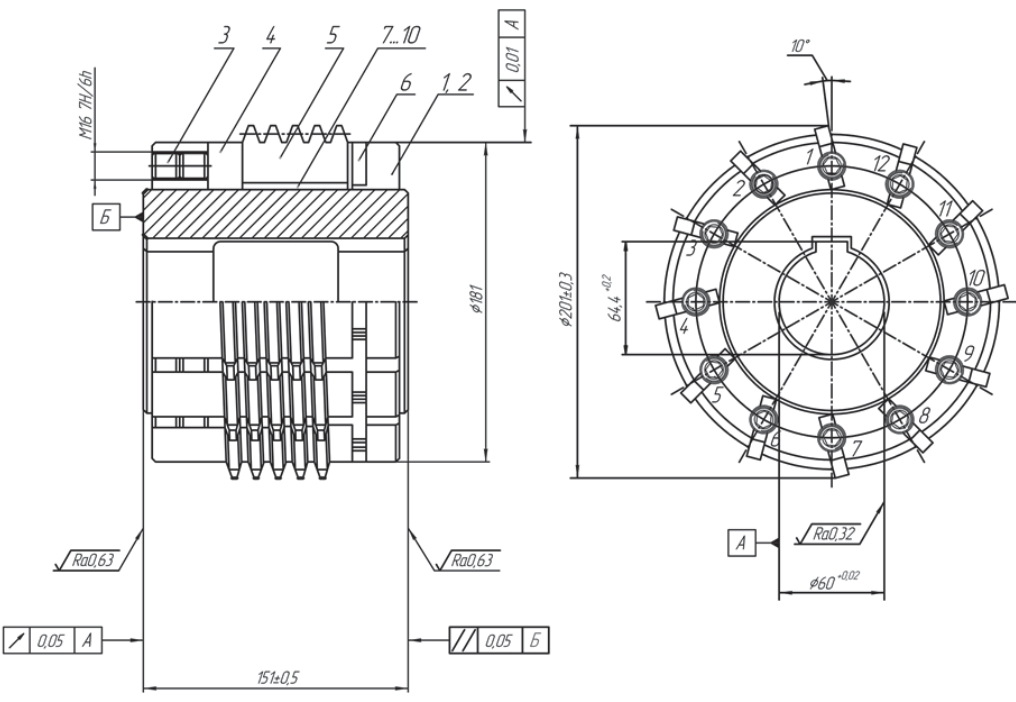
regrinding.

Thus, milling cutters of this design, calculated according to theoretically accurate dependencies, are able to provide higher accuracy of the part teeth. This circumstance will allow the milling cutter to be used not only for preliminary, but also for final processing.

The kinematic angles were studied within current issue from the point of view of the working conditions of the racks.

\section{The numerical analysis of the kinematic parameters of evolvent worm cutters with carbide racks}

The studies were carried out on the example of a cylindrical helical gear with a module $m=4 \mathrm{~mm}$ and an angle of inclination of the teeth at the initial diameter $\beta=20^{\circ}$.

The calculation was carried out for an evolvent worm cutter with an outer diameter of $200 \mathrm{~mm}$ and a front static angle $\gamma_{a 0}=-10^{\circ}$ [13].

The results of calculation are presented in the graphs of Fig. 3-5.

The oscillation of the working rake (front) angle in the interval from the moment of cutting to the moment the tool leaves the part is shown in Fig. 3. The analysis allows us to conclude that the values of $\gamma_{\mathrm{pn}}$ varied within:

- for the right side $\gamma_{p n}=$ $=-4,5^{\circ} \ldots-5,3^{\circ}$ and reaches a maximum at the time of cutting the largest allowance thickness;

- for the left side $\gamma_{p n}=$ $=-2,1^{\circ} \ldots-2,4^{\circ}$ and reaches a minimum at the time of cutting the smallest allowance thickness.

The dynamics of changes in the working rear angle $\alpha_{p n}$ is opposite - it reaches a maximum at the time of
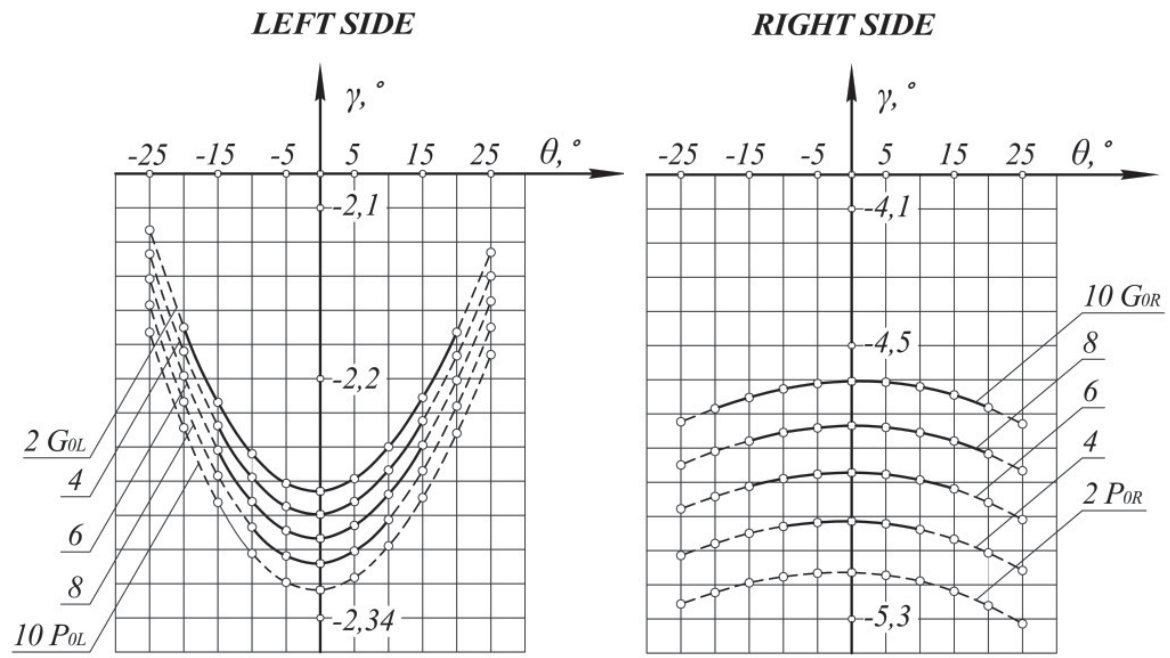

- cutter tooth profile ed in cutting

---- cutter tooth profile olved in cutting

Fig. 3. Change in the front angle during cutting at each profile point with $\mathrm{I}=0$ 


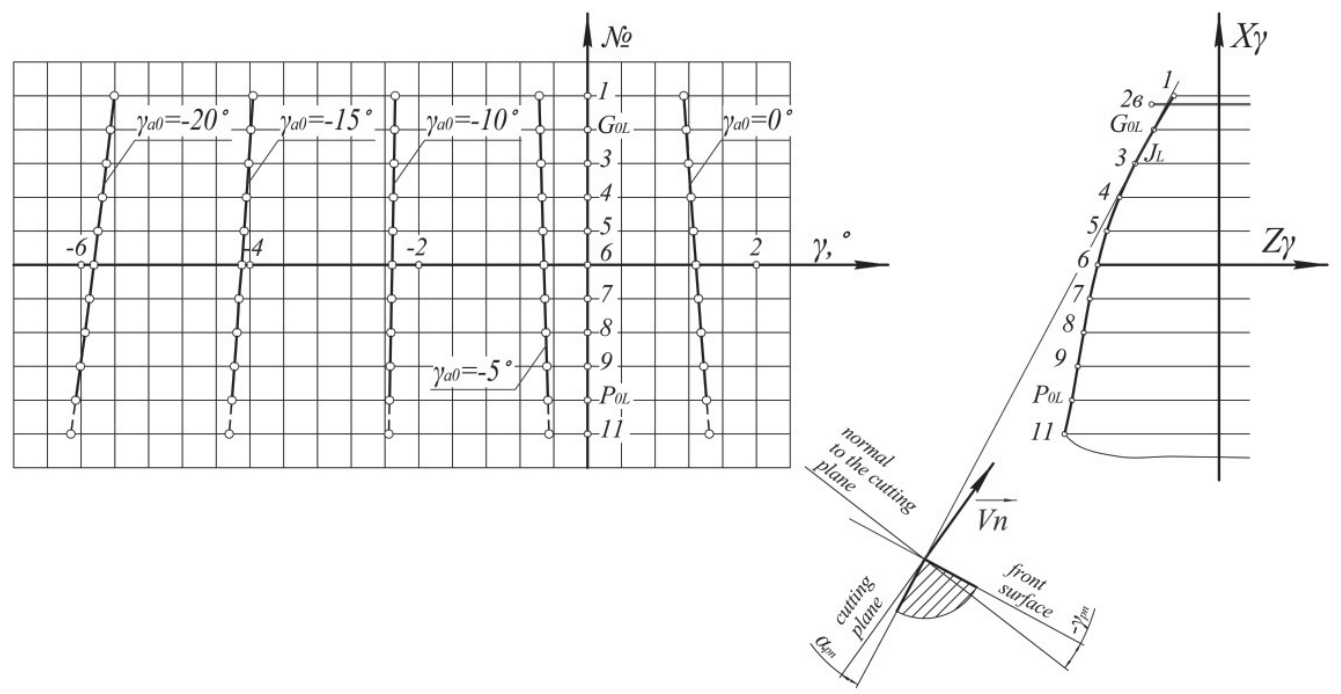

Fig. 4a. Change in kinematic rake angles on the left side of the tooth profile at $\gamma_{a 0}=0^{\circ} ;-5^{\circ} ;-10^{\circ} ;-15^{\circ} ;-20^{\circ}$ at $l=0, \theta=0$

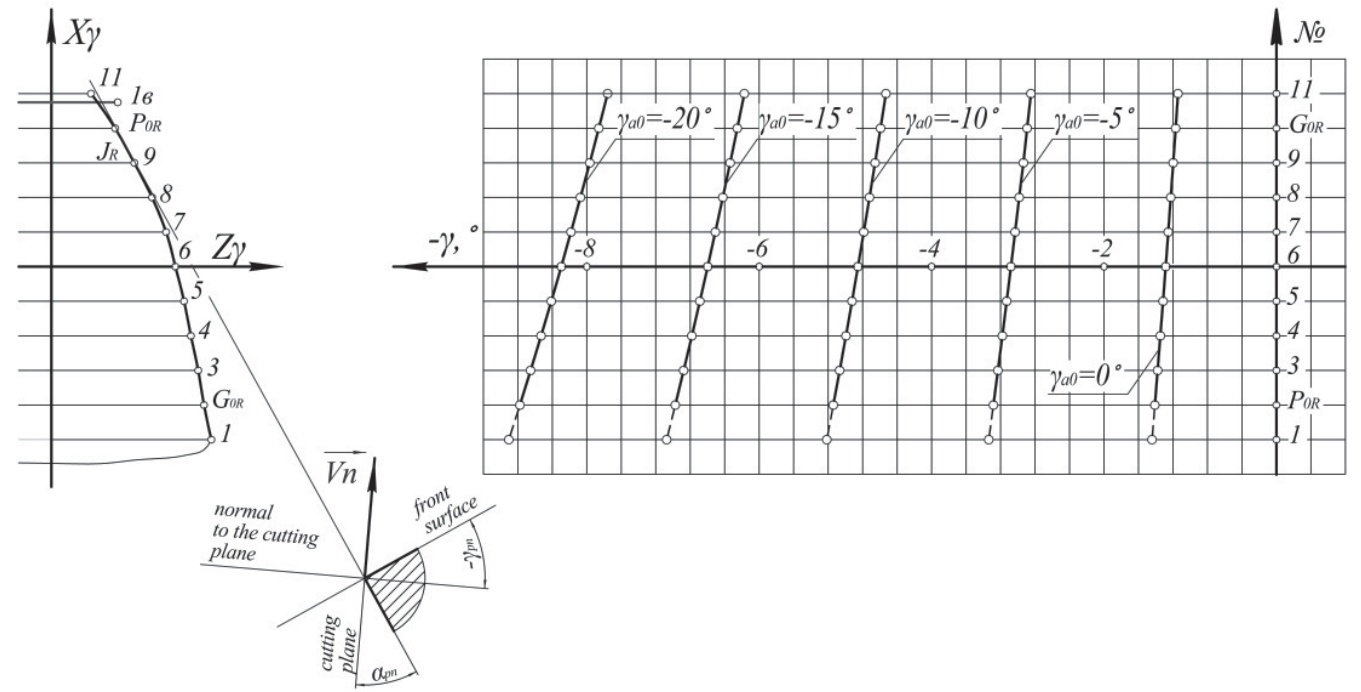

Fig. 4b. Change in kinematic rake angles on the right side of the tooth profile at $\gamma_{a 0}=0^{\circ} ;-5^{\circ} ;-10^{\circ} ;-15^{\circ} ;-20^{\circ}$ at $l=0, \theta=0$

cutting the smallest allowance for the left side and a minimum at the time of cutting the largest allowance for the right side. This must be taken into account when designing a cutting tool due to the fact that the value of the static predetermined angle is not preserved during the cutting process.

The nature of the change in the values of the working front cutting angle, depending on the assigned static front angle $\gamma_{a 0}$, is shown in Fig. 4.

With an increase in $\gamma_{a 0}$ :

- the working front angle $\gamma_{p n}$ decreases;

- the working rear angle $\alpha_{p n}$ increases.

At $\gamma_{a 0}=0^{\circ}$, the working rake (front) angle on the left side of the tooth profile takes a positive value, and $\alpha_{p n}$ is negative, which does not satisfy the cutting conditions. At $\gamma_{a 0}=-5^{\circ}$, the working $\alpha_{p n}<2^{\circ}$, which also does not satisfy the cutting conditions. At $\gamma_{a 0}=-10^{\circ},-15^{\circ},-20^{\circ}$ the cutting angles does not go beyond acceptable values: $\gamma_{p n}<0^{\circ}, \alpha_{p n}>2^{\circ}$.

The influence of the outer diameter of the cutter on the kinematic angles is shown in Fig. 5.
The working front angles on the left side are smaller, and with $\mathrm{D}_{\mathrm{a} 0}=150 \mathrm{~mm}$ the rear working angle go beyond the boundaries of an acceptable value $\alpha_{\mathrm{pn}}<2^{\circ}$. With other parameters being equal and with an increase in the outer diameter of the tool, the kinematic angles take on values that satisfy the cutting conditions.

\section{Conclusions}

An analysis of the results shows that at a constant cutter speed, wheel speed and feed, the cutting angles depend in a large extent on the design parameters of the tool - the static angle $\gamma_{a 0}$ given by the designer and the outer diameter $d_{a 0}$ of the evolvent worm cutter.

Thus, based on the kinematic analysis of the worm cutter with axial grooves with carbide teeth, the following values of the static rake angle are established at which the optimal cutting process condition is achieved:

- rake angle $\gamma_{a 0}=-10^{\circ} \ldots-15^{\circ}$. 


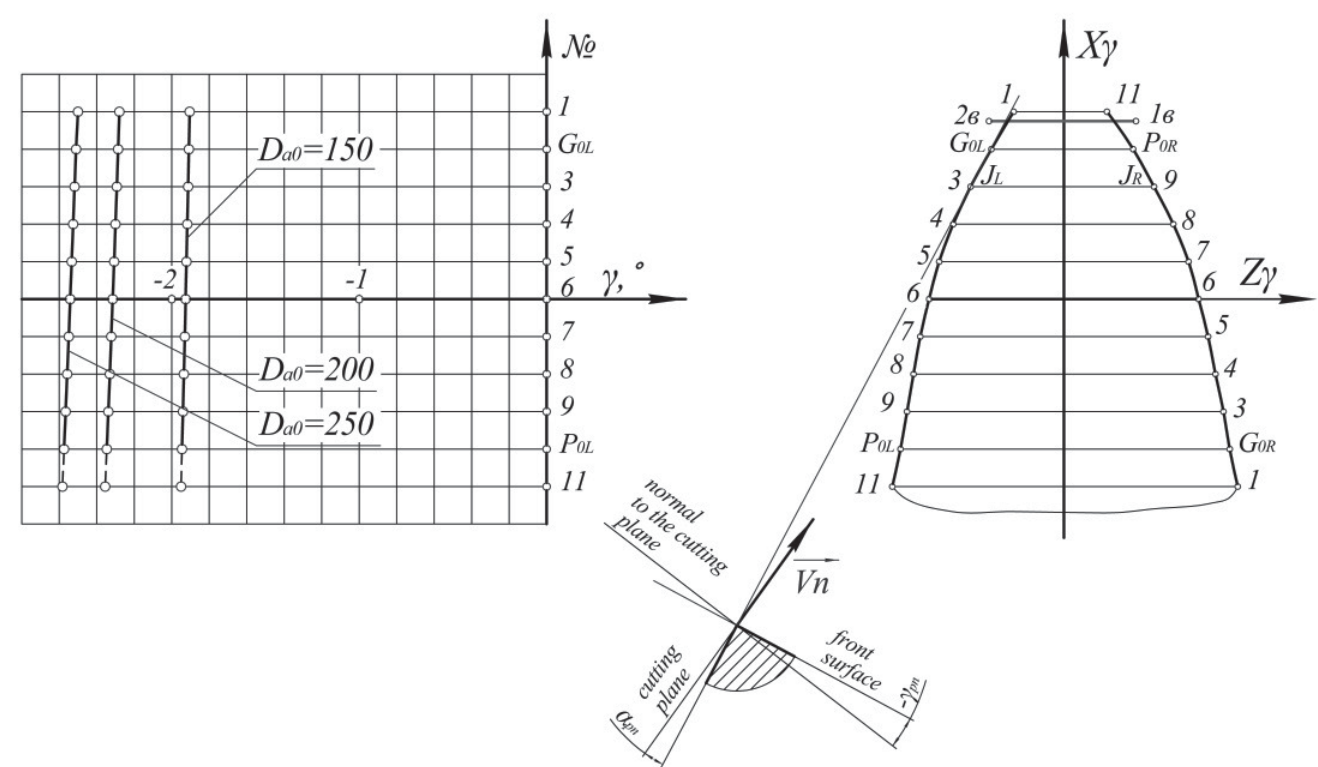

Fig. 5a. Change in kinematic rake angles on the left side of the tooth profile when $D_{a 0}=150 \mathrm{~mm} ; 200 \mathrm{~mm} ; 250 \mathrm{~mm}$ at $l=0, \theta=0$

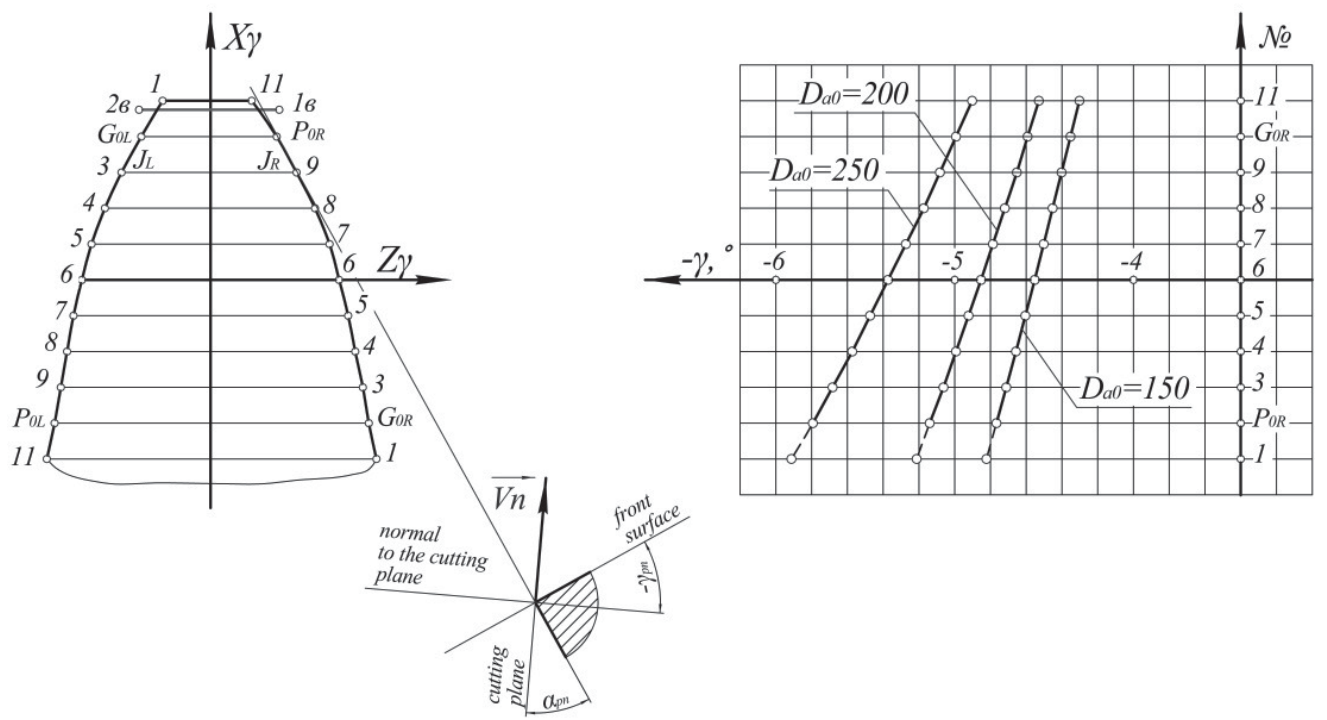

Fig. 5b. Change in kinematic rake angles on the right side of the tooth profile at $D_{a 0}=150 \mathrm{~mm} ; 200 \mathrm{~mm} ; 250 \mathrm{~mm}$ at $l=0, \theta=0$

\section{REFERENCES}

1. Tseng J. T., Tsay C. B. Mathematical model and surface deviation of cylindrical gears with curvilinear shaped teeth cut by a hob cutter. ASME J. Mech. Des. 2005. Vol. 127. pp. 982-987.

2. Mate M., Hollanda D. About the profile accuracy of the involute gear hob. Electrical and Mechanical Engineering. 2017. Vol. 9. pp. 5-18

3. Feofilov N. D., Skryabin V. N., Vorobev I. A., Yanov E. S., Effect of regrindings and the geometry of the front surfaces of a prefabricated worm cutter on the profile of gears. Izvestiya Tulskogo gosudarstvennogo universiteta. Seriya "Tekhnicheskie nauki". 2016. Vol. 7. Part 2. pp. 86-92.

4. Pat. Germany US 2019 / 0232405 A1, B23F 21/16. Hobbing tool with replaceable cutting inserts. Andrea Consonni. Filed: Apr. 7, 2017, Date: Dec. 19, 2018.

5. Pat. KR 20130043511 (A), B23F 21/16. Assembly type hob for cutting gear. Yoon Sung Dug. Date: April 30, 2013.

6. Pat. Russian Federation 2680122 C1, IPC B23F 21/16. Combined worm cutter. Artamonov E. V., Kireev V. V., Zyryanov V.A. No. 2017146947; declared December 28, 2017; publ. 02/15/2019.

7. Artamonov E. V., Kireev V. V., Zyryanov V. A., Improving the Efficiency of Hobbing Mills. Russian Engineering Research. 2017. Vol. 37. No. 5. pp. 447-449. DOI: 10.3103/S1068798X17050057.
8. Sovilj-Nikić I. Application of genetic algorithm in optimization of geometric parameters of hob milling tool (Primena genetskog algoritma u optimizaciji geometrijskih parametara odvalnog glodala). Fakultet tehničkih nauka. Novi Sad. Serbia. Master Thesis. 2007.

9. Hsu R. H., Fong J. H. Novel variable-tooth-thickness hob for longitudinal crowning in the gear-hobbing process. Mechanism and Machine Theory. 2011. Vol. 46. pp. 1084-1096.

10. Radzevich S. P. A novel design of cylindrical hob for machining of precision involute gears. ASME J. Mech. Des. 2007. Vol. 129. pp. 334-345.

11. Radzevich S. P. Design of a special-purpose hob with prescribed value of the hob-setting angle for machining of cluster gear. ASME J. Mech. Des. 2007. Vol. 129. pp. 438-444.

12. Boriskin O. I., Stakhanov N. G., Astapova I. V. Error analysis of evolvent worm milling cutters with carbide-tipped multi-faceted inserts. Chernye metally. 2019. No. 5. pp. 22-27.

13. Boriskin O. I., Stakhanov N. G., Astapova I. V. Methods for improving the accuracy of technological and carbide inserts. High-tech technologies in mechanical engineering. 2019. No. 4. pp. 3-6. 